\title{
Genetic Diversity of Uropathogenic Escherichia coli Isolated from Human T Lymphotropic Virus Type I (HTLV-I) Infected Individuals
}

\author{
Andréia Santos Silva1, Elizabeth de Souza Neves², Maria Cristina Lourenço², \\ Márcia dos Santos Guimarães ${ }^{3}$, Debora Ribeiro de Souza Santos¹, \\ Adriana Hamond Regua-Mangia ${ }^{1}$ \\ ${ }^{1}$ Escola Nacional de Saúde Pública Sergio Arouca, Fundação Oswaldo Cruz, Rio de Janeiro, Brazil \\ ${ }^{2}$ Instituto Nacional de Infectologia, Fundação Oswaldo Cruz, Rio de Janeiro, Brazil \\ ${ }^{3}$ Instituto Nacional de Controle de Qualidade em Saúde, Fundação Oswaldo Cruz, Rio de Janeiro, Brazil \\ Email: regua@ensp.fiocruz.br
}

How to cite this paper: Silva, A.S., de Souza Neves, E., Lourenço, M.C., dos Santos Guimarães, M., de Souza Santos, D.R. and Regua-Mangia, A.H. (2016) Genetic Diversity of Uropathogenic Escherichia coli Isolated from Human T Lymphotropic Virus Type I (HTLV-I) Infected Individuals. $A d$ vances in Infectious Diseases, 6, 163-173. http://dx.doi.org/10.4236/aid.2016.64020

Received: November 5, 2016

Accepted: December 5, 2016

Published: December 8, 2016

Copyright $\odot 2016$ by authors and Scientific Research Publishing Inc. This work is licensed under the Creative Commons Attribution International License (CC BY 4.0).

http://creativecommons.org/licenses/by/4.0/

(c) (i) Open Access

\begin{abstract}
Urinary tract infection (UTI) is a frequent pathology among HTLV-I+ individuals being capable of severely compromising the kidneys and bladder. Molecular characteristics of uropathogenic Escherichia coli (UPEC) from HTLV-I+ infected individuals are unknown. UPEC isolates from HTVL-I+ individuals, with and without clinical symptoms of myelopathy, were submitted to genetic typing seeking to infer bacterial diversity and potential virulence. 71 bacterial isolates were characterized according to random amplified polymorphic DNA and phylotypes. Phylotyping classified $E$. coli into four phylogenetic groups: A (18.3\%), B1 (16.9\%), B2 (39.4\%), and D (25.3\%) and 8 phylotypes according to the presence of the genetic sequences chuA, yja $A$ and the DNA fragment TSPE4.C2:--- (5.6\%) and -+- (12.6\%) in phylogroup $\mathrm{A},--+(7.0 \%)$ and $-++(9.8 \%)$ in $\mathrm{B} 1,+++(32.3 \%)$ and $++-(7.0 \%)$ in $\mathrm{B} 2,+--$ $(15.4 \%)$ and $+-+(9.8 \%)$ in $\mathrm{D}$. The $\mathrm{B} 2$ phylogroup was the most prevalent among HTLV- associated myelopathy and asymptomatic individuals. RAPD-PCR typing revealed a high degree of bacterial polymorphism indicating a non-clonal origin. Genotypes were not found to be distributed according to clinical status or epidemiological features. Our results lead us to suggest that the neurological impairment in HTLV-I+ individuals can be a risk factor for urinary infections due E. coli which are caused by distinct bacterial lineages.
\end{abstract}

\section{Keywords}

Uropathogenic Escherichia coli, Genetic Diversity, Phylotype, HTLV-I+ 


\section{Introduction}

The Human T-lymphoytropic type I (HTLV-I) is a retrovirus associated with a chronic myelopathy known as HTLV-I-Associated Myelopathy or Tropical Spastic Paraparesis (HAM/TSP) [1]. HAM/TSP is a progressive neurologic disorder characterized by leg weakness, diffuse hyperreflexia, clonus, loss of vibration sense, and detrusor insufficiency leading to bladder dysfunction. Central Africa, Japan, the Caribbean, South America and Melanesia are the principal endemic areas for HTLV-I [2]. The majority of HTLV-I-infected individuals are clinically asymptomatic and less than $5 \%$ of seropositive subjects develop HAM/TSP [1] [3] [4]. Urologic manifestations are present in up $90 \%$ of patients with HAM/TSP and are characterized by frequency, urgency and urge incontinence [1] [5] [6] [7]. Epidemiological studies have described that HTLV-I+ individuals have a higher prevalence and incidence of urinary symptoms than seronegative controls [5] [6] [8] [9]. Urinary tract infection (UTI) is an extremely frequent pathology among HTLV-I+ individuals due to the occurrence of bladder dysfunctions favoring colonization by bacteria [6] [8] [9] [10]. These urinary infections can be clinically relevant, being capable of severely compromising the kidneys and bladder [11]. However, bladder impairment depends on the stage of development of the illness [10]. With the advancement of the degree of motor impairment, the exacerbation of urinary symptoms has been observed, with the development of systematic complications even being possible [5] [6] [9]. Studies which investigate the etiology of UTIs in HTLV-I+ patients found that Escherichia coli is a bacterial species relevant in urinary infections; however, the genetic characteristics of these microorganisms isolated in this group of individuals are little known [9]. Recent studies have shown a great variety of molecular methodologies utilized as diagnostic tools, as well as for typing purposes, allowing the detection of diversity, inference of genetic interrelation, and correlation with the clinical-epidemiological context. Among the molecular techniques used for the study of diversity in $E$. coli populations, the technique of random amplification of polymorphic DNA (RAPD-PCR) has received special attention as a typing method due to its simplicity of execution, low cost, flexibility, discriminatory power, and reproducibility under standardized experimental conditions. These studies have allowed the detection of the circulation of particular genetic lineages and revealed that $E$. coli epidemiologically correlated share urovirulence properties which are relevant for the determination and evolution of the clinical conditions [12] [13]. Phylogenetic analysis has significantly contributed to the elucidation of the pathogenic potential of E. coli populations. This molecular characterization has allowed the designation of the main phylogenetic groups: A, B1, B2, and D [14]. The microorganisms belonging to these distinct phylogroups are genetically diverse and differ according to metabolic properties, ecological niches, and the capacity to cause disease [15] [16]. E. coli belonging to group B2, and to a lesser extent from $\mathrm{D}$, have frequently been associated with extra-intestinal infections, while commensal E. coli and diarrheagenic strains are normally found as members from groups A, B1, and D [15] [16] [17] [18].

In this study, we characterized uropathogenic E. coli (UPEC) isolates from HTVL-I+ 
individuals, with and without clinical myelopathy symptoms, by the random amplification of polymorphic DNA (RAPD) and PCR-multiplex seeking to infer bacterial diversity, genetic interrelations and potential virulence.

\section{Methods}

\subsection{Bacterial Samples and Participants}

A total of 71 Escherichia coli isolates from adult individuals treated at the Laboratório de Pesquisa em Neuroinfecções do Instituto Nacional de Infectologia (INI/Fiocruz), with positive urine culture, and HTLV-I+ serology were included in this study. E. coli was isolated in the Laboratório de Bacteriologia e Bioensaios (INI/Fiocruz). For patients with clinical symptoms of myelopathy, neurological impairment was determined based on the Expanded Scale of the State of Incapacity (ESSI) [19]. Out of all of the $E$. coli isolates, 35 were obtained from HTLV-I associated myelopathy patients (HAM/ TSP), presenting different degrees of neurological impairment (EDSS $>0$ to EDSS $<7$ ) and, 36 isolates were recovered from individuals without clinical myelopathy symptoms (EDSS $=0$, asymptomatic) (Table 1 ). Clinical-epidemiological data were obtained from the electronic records. The study protocol was approved by the Instituto Nacional de Infectologia and Escola Nacional de Saúde Pública Sergio Arouca Ethics Committee on Human Research, Fundação Oswaldo Cruz (CAEE 0071.0.009.031-07/ CAAE 0022.0.031.000-10).

\subsection{Random Amplification of Polymorphic DNA}

RAPD-PCR was used as the molecular typing technique with the primers A04 (AATCGGGCTG), 1254 (CCGCAGCCAA), and M13 (GAGGGTGGCGCTTCT) [20]. RAPD profiles were inspected visually and defined according to the presence or absence and intensity of polymorphic bands. A $1 \mathrm{~Kb}$ DNA ladder was used as a molecular weight marker (Invitrogen). Semi automated analysis used the UVI Soft Image Acquisition and Analysis Software, program UVIProBandmap, version 11.9 (Uvitec, Cambridge). Cluster analysis was done by using the unwieghted pair group method with arithmetric averages (UPGMA) of the Image Analysis System. The percentages of similarity were estimated by Dice coefficient. The reproducibility of RAPD amplifications was assessed using the selected primers with different DNA samples isolated independently from the same strain and amplified at different times. Numerical index of the discriminatory ability of RAPD primers was calculated by applying Simpson's Index of Diversity equation [21].

\subsection{PCR-Triplex for E. coli Phylotyping}

PCR assay was performed using phylogenetic group specific primers for the genes chuA.1/chuA.2, yjaA.1/yjaA.2 and the DNA fragment TSPE4C2.1/TSPE4C2.2 [14]. A, $\mathrm{B} 1, \mathrm{~B} 2$ and D phylogroups and respective allelic variants (phylotypes) were determined based on the presence or absence of bands according to previously defined criteria in the triplex amplification assay. To estimate the size of the fragments a 100 bp DNA 
Table 1. Escherichia coli identification and clinical aspects of HTLV-I seroposite individuals.

\begin{tabular}{|c|c|c|c|c|c|c|c|c|}
\hline \multicolumn{5}{|c|}{${ }^{\mathrm{a}} \mathrm{HAM}$ patients } & \multicolumn{4}{|c|}{ Asymptomatic carries } \\
\hline $\begin{array}{l}\text { E. coli } \\
\text { isolate }\end{array}$ & ${ }^{\mathrm{b}} \operatorname{Sex}$ & Age (years) & $\begin{array}{l}{ }^{c} \text { EDSS } \\
\text { Score }\end{array}$ & ${ }^{\mathrm{d}} \mathrm{UTI}$ & $\begin{array}{l}\text { E. coli } \\
\text { isolate }\end{array}$ & ${ }^{\mathrm{b}} \operatorname{Sex}$ & Age (years) & ${ }^{\mathrm{d} U T I}$ \\
\hline I 01 & M & 36 & 7 & $\mathrm{~A}^{*}$ & I 03 & $\mathrm{~F}$ & 26 & S \\
\hline I 02 & M & 36 & 7 & A & I 06 & $\mathrm{~F}$ & 58 & S \\
\hline I 07 & M & 58 & 6 & $\mathrm{~S}^{* *}$ & I 08 & $\mathrm{~F}$ & 56 & A \\
\hline I 09 & $\mathrm{~F}$ & 63 & 7 & A & I 17 & $\mathrm{~F}$ & 39 & A \\
\hline I 12 & $\mathrm{~F}$ & 74 & 7 & A & I 19 & $\mathrm{~F}$ & 31 & A \\
\hline I 16 & $\mathrm{~F}$ & 47 & 6 & $S$ & I 20 & $\mathrm{~F}$ & 50 & $S$ \\
\hline I 24 & $\mathrm{~F}$ & 52 & 4 & A & I 22 & $\mathrm{~F}$ & 34 & S \\
\hline I 25 & $\mathrm{~F}$ & 52 & 4 & $\mathrm{~A}$ & I 32 & $\mathrm{~F}$ & 46 & A \\
\hline I 27 & $\mathrm{~F}$ & 44 & 7 & $S$ & I 34 & $\mathrm{~F}$ & 21 & A \\
\hline I 28 & $\mathrm{~F}$ & 67 & 7 & $S$ & I 37 & $\mathrm{~F}$ & 44 & S \\
\hline I 30 & $M$ & 52 & 7 & A & I 38 & $\mathrm{~F}$ & 49 & $S$ \\
\hline I 35 & $\mathrm{~F}$ & 64 & 5 & A & I 41 & $\mathrm{~F}$ & 44 & A \\
\hline I 40 & $\mathrm{~F}$ & 35 & 6 & $S$ & I 42 & $\mathrm{~F}$ & 67 & A \\
\hline I 45 & $\mathrm{~F}$ & 35 & 6 & $S$ & I 43 & $\mathrm{~F}$ & 28 & A \\
\hline I 46 & $\mathrm{~F}$ & 58 & 7 & $S$ & I 49 & $\mathrm{~F}$ & 31 & $S$ \\
\hline I 47 & $\mathrm{~F}$ & 37 & 7 & A & I 50 & M & 36 & A \\
\hline I 55 & $\mathrm{M}$ & 39 & 7 & A & I 51 & $\mathrm{~F}$ & 50 & A \\
\hline I 61 & $\mathrm{~F}$ & 46 & 7 & $S$ & I 56 & $\mathrm{~F}$ & 16 & A \\
\hline I 64 & $\mathrm{~F}$ & 62 & 4 & A & I 57 & $\mathrm{M}$ & 25 & A \\
\hline I 68 & $\mathrm{~F}$ & 46 & 7 & $S$ & I 59 & $\mathrm{~F}$ & 33 & A \\
\hline I 69 & $\mathrm{~F}$ & 33 & 7 & $S$ & I 60 & $\mathrm{~F}$ & 33 & $S$ \\
\hline I 70 & $\mathrm{~F}$ & 53 & 4 & S & I 62 & $\mathrm{~F}$ & 54 & S \\
\hline I 71 & $\mathrm{~F}$ & $?$ & $?$ & $S$ & I 63 & F & 16 & S \\
\hline I 73 & $\mathrm{~F}$ & 63 & 1 & $S$ & I 66 & $\mathrm{~F}$ & 82 & S \\
\hline I 79 & $\mathrm{~F}$ & 46 & 7 & $S$ & I 67 & $\mathrm{~F}$ & 23 & $S$ \\
\hline I 80 & F & 43 & 6 & S & I 74 & $\mathrm{~F}$ & 24 & A \\
\hline I 82 & $\mathrm{~F}$ & 59 & 7 & S & I 78 & $\mathrm{~F}$ & 34 & A \\
\hline I 84 & $\mathrm{~F}$ & 59 & 7 & $S$ & I 81 & $\mathrm{~F}$ & 24 & S \\
\hline I 87 & $\mathrm{~F}$ & 77 & 7 & S & I 83 & $\mathrm{~F}$ & 53 & A \\
\hline I 90 & $\mathrm{~F}$ & 31 & 7 & A & I 85 & $\mathrm{~F}$ & 40 & A \\
\hline I 92 & F & 52 & 7 & A & I 86 & $\mathrm{~F}$ & 79 & A \\
\hline I 94 & F & 56 & 7 & A & I 88 & M & 48 & A \\
\hline I 96 & $\mathrm{~F}$ & 59 & 7 & A & I 89 & M & 60 & S \\
\hline I 97 & F & 37 & 7 & A & I 91 & $\mathrm{~F}$ & 36 & A \\
\hline I 98 & $\mathrm{~F}$ & 57 & 6 & A & I 93 & M & 68 & S \\
\hline- & - & - & - & - & I 95 & F & 48 & A \\
\hline
\end{tabular}

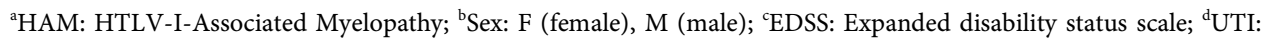
Urinarytract infection; $\mathrm{S}^{*}$ : symptomatic; $\mathrm{A}^{* *}$ : asymptomatic. 
ladder was used. Molecular assays included a nontemplate reaction and the clinical UPEC strain 119C (UPEC chuA+, yjaA + and TSPE4.C2+) as the positive control [16].

\subsection{Statistical Analysis}

Results were compared and analyzed using the Fisher exact test, Epi Info program, version 3.5.1. P-value $\leq 0.05$ was considered statistically significant.

\section{Results and Discussion}

Our study investigated the genetic diversity and the phylogenetic groups of $71 \mathrm{E}$. coli uropathogenic isolates recovered from HTLV-I+ individuals, with and without clinical myelopathy symptoms. RAPD typing revealed high levels of polymorphism that are consistent with previously reported observations for E. coli [22]. Escherichia coli has been recognized as a genetically diverse species with a complex phylogeny, broad virulence factors armament and significant genomic plasticity, comprising non-pathogenic gut commensals and strains responsible for intestinal and extra-intestinal disease [22] [23] [24]. The diversity is especially observed among extra-intestinal E. coli (ExPEC) strains. Unlike commensal E. coli, ExPEC have the ability to cause diseases once outside the host gut reservoir due to the possession of a wide range of pathogenic virulence factors and horizontal gene transfer [24] [25]. RAPD clustering showed a diverse bacterial population constituted by small clonal groups, with indexes of similarity varying from $31 \%-89 \%, 9 \%-80 \%$, and $23 \%-95 \%$ for the primers A04, 1254, and M13, respectively. The overall chromosomal analysis of $E$. coli isolates from HTLV-associated myelopathy and asymptomatic individuals, showed distinct genetic background which is consistent with previous observations with nonrelated epidemiological strains and thus characterizing distinct evolutionary lineages. The reactions employing the primers A04, M13, and 1254 resulted in 62, 58, and 56 reproductive profiles respectively (Figure 1, Figure 2). The discriminatory power of the primers assessed by the diversity equation revealed indexes of 97.9\% (primer A04), 96.7\% (M13), and 94.9\% (1254). The number of polymorphic bands varied from $4-10$ to 1 - 11 for the primers A04 and 1254, respectively. The primer M13 generated more complex electrophoretic patterns. For the E. coli isolates in the HAM/TSP group $(\mathrm{n}=35), 35,29$, and 28 electrophoretic profiles were detected for the primers A04, 1254, and M13, respectively, with the number of polymorphic bands varying from 4 - 9 (A04), 1 - 9 (1254), and 4 - 25 (M13). Using the primer 1254, 17 RAPD patterns were observed for isolates recovered from the patients presenting high degree of neurological impairment (score 7). From the total 22 isolates in this HAM/TSP group, 8 profiles were detected in patients with symptomatic urinary infection $(n=10)$ and 9 in the asymptomatic UTI group $(n=9)$. In the HAM/TSP group EDSS score $6(n=6), 5$ electrophoretic profiles were observed distributed among patients with UTI symptomatic $(\mathrm{n}=5)$ and asymptomatic infection $(\mathrm{n}=$ 1). For the HAM/TSP groups scores $5(n=1)$ and $4(n=4), 1$ and 4 electrophoretic patterns were found mainly distributed among the asymptomatic patients, respectively. The different primers used to investigate the overall chromosomal diversity among $E$. 
coli from HAM/TSP group were strongly correlated. No common RAPD pattern was observed between $E$. coli isolates recovered from individuals with distinct EDSS scores. RAPD patterns generated by primers A04 and M13 also exhibited similar distribution according to the urinary symptomatology and EDSS score. In general, identical RAPD profiles were mainly observed in E. coli isolates recovered from the same patient at distinct times, suggesting the occurrence of urinary tract infection recurrence. In the group of asymptomatic individuals $(\mathrm{n}=36)$, RAPD reactions performed with primers M13, A04, and 1254 resulted in 30, 27, and 26 different profiles, respectively. The total number of polymorphic bands was 4 - 10 (A04), 5 - 11 (1254), and 6 - 15 (M13). In this group of individuals, common RAPD types were mainly observed in E. coli isolates recovered from the same individual.

Clinical-epidemiological parameters of the HTLV-I+ individuals such as sex, age, degree of neurological impairment, and clinical UTI condition, were not considered re-

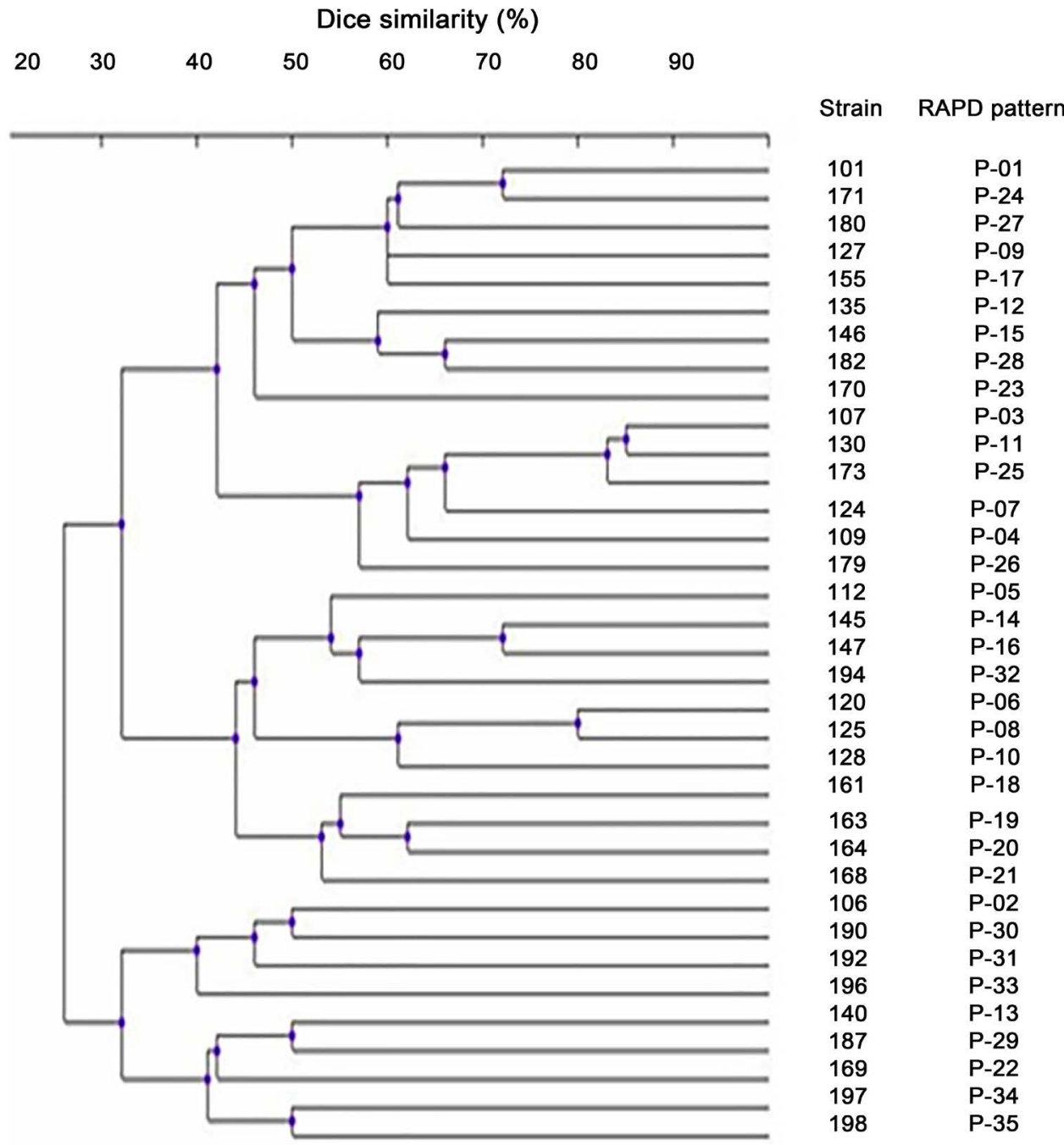

Figure 1. Dendrogram generated by the Dice coefficient and clustering by unweighted pair group method with arithmetric averages and respective RAPD numeric profiles (primer 1254) of E. coli isolates from HLTV-I seropositive individuals with myelopathy. 


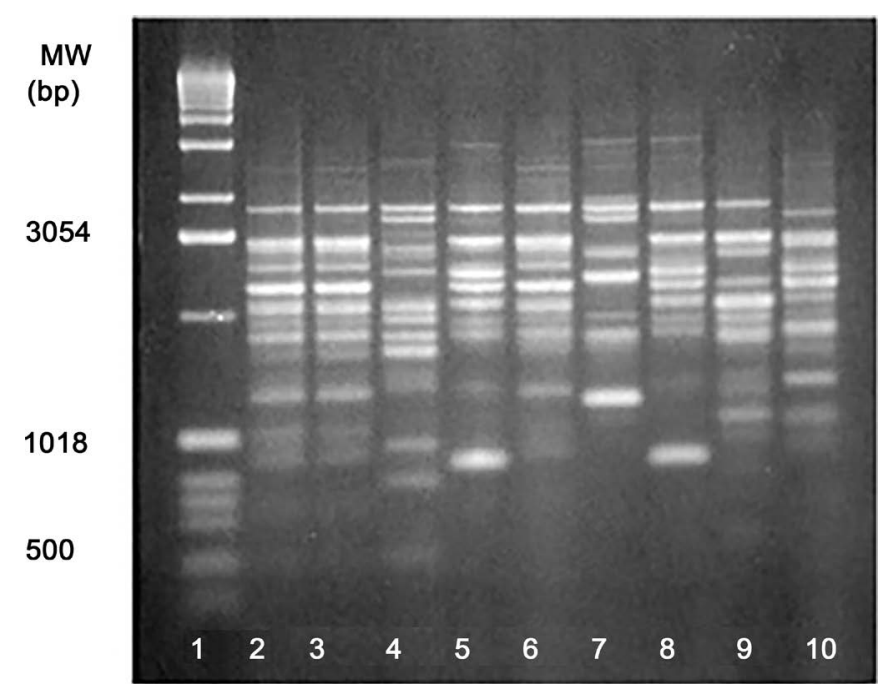

Lane 1: $1 \mathrm{~Kb}$ DNA Ladder; Lane 2: I01; Lane 3: I02; Lane 4: I07; Lane 5: I09; Lane 6: I12; Lane 7: I16; Lane 8: I24; Lane 9: I25; Lane 10: I27.

Figure 2. RAPD-PCR profiles (primer A04) of representative E.coli isolates from HLTV-I seropositive individuals with myelopathy.

levant for the RAPD-PCR types distribution and the genetic relatedness of E. coli isolates. The overall chromosomal analysis of UPEC isolates from HTLV-associated myelopathy and asymptomatic individuals, showed distinct genetic background which is consistent with previous observations with nonrelated epidemiological strains and thus characterizing distinct evolutionary lineages [22].

Clermont genotyping was used to assign the diversity and to characterize the potential virulence within E. coli isolates (Table 2, Figure 3). The results obtained classified the E. coli into four phylogenetic groups: A (18.3\%), B1 (16.9\%), B2 (39.4\%), and D (25.3\%). The B2 phylogroup was the most common among the bacterial isolates as much in the HAM/TSP group of patients as with asymptomatic patients, corresponding to $31.5 \%(n=11 / 35)$ and $47.2 \%(n=17 / 36)$, respectively. The distribution of the phylogroups A, B1, and D corresponded to $21 \%(\mathrm{n}=8 / 35), 20 \%(\mathrm{n}=7 / 35)$, and $25.8 \%(\mathrm{n}=$ $9 / 35)$ in the HAM/TSP group and to $13.9 \%(\mathrm{n}=5 / 36), 13.9 \%(\mathrm{n}=5 / 36), 25 \%(\mathrm{n}=$ 9/36), in the asymptomatic patient group. Studies on molecular epidemiology have shown that the occurrence of $E$. coli phylogroups varies according to the characteristics of the population, associated pathologies, and the geographical region. However, the B2 phylogroup is the most prevalent among extra-intestinal infections caused by these microorganisms and is particularly prominent among more virulent isolates associated with urinary tract infections. The other phylogroups are also seen in urinary tract infections, however at a lower frequency and with a distribution associated with particular epidemiological contexts. Considering the degree of neurological impairment, the $E$. coli isolates belonging to the B2 phylogroup were recovered from patients with HAM/TSP presenting EDSS $>0$ and $<7$. The bacterial isolates belonging to the phylogroups A and B1 were obtained from patients with a greater degree of neurological impairment (EDSS > 6). The distribution of phylogroups according to the clinical states of 
Table 2. Phylotype distribution among E. coli isolates recovered from individuals with and without HTLV-associated myelopathy.

\begin{tabular}{ccccccc}
\hline \multirow{2}{*}{ Phylogroup } & \multicolumn{3}{c}{ Genetic markers } & \multicolumn{5}{c}{ Phylotype distribution } \\
\cline { 2 - 7 } & chuA & yjaA & TSPE4.C2 & ${ }^{a} H A M / T S P(\%)$ & asymptomatic (\%) & Total (\%; -value) \\
\hline A & - & - & - & $3(8.60)$ & $1(2.80)$ & $4(5.60 ; 0.71)$ \\
A & - & + & - & $5(14.3)$ & $4(11.1)$ & $9(12.6 ; 0.82)$ \\
B1 & - & - & + & $4(11.4)$ & $1(2.80)$ & $5(7.0 ; 0.44)$ \\
B1 & - & + & + & $3(8.60)$ & $4(11.1)$ & $7(9.8 ; 0.84)$ \\
B2 & + & + & + & $10(28.6)$ & $13(36.1)$ & $23(32.3 ; 0.68)$ \\
B2 & + & + & - & $1(2.80)$ & $4(11.1)$ & $5(7.0 ; 0.27)$ \\
D & + & - & - & $7(20.0)$ & $4(11.1)$ & $11(15.4 ; 0.29)$ \\
D & + & - & + & $2(5.70)$ & $5(13.9)$ & $7(9.80 ; 0.31)$ \\
\hline
\end{tabular}

${ }^{a}$ HAM/TSP, HTLV-I-Associated Myelopathy or Tropical Spastic Paraparesis.

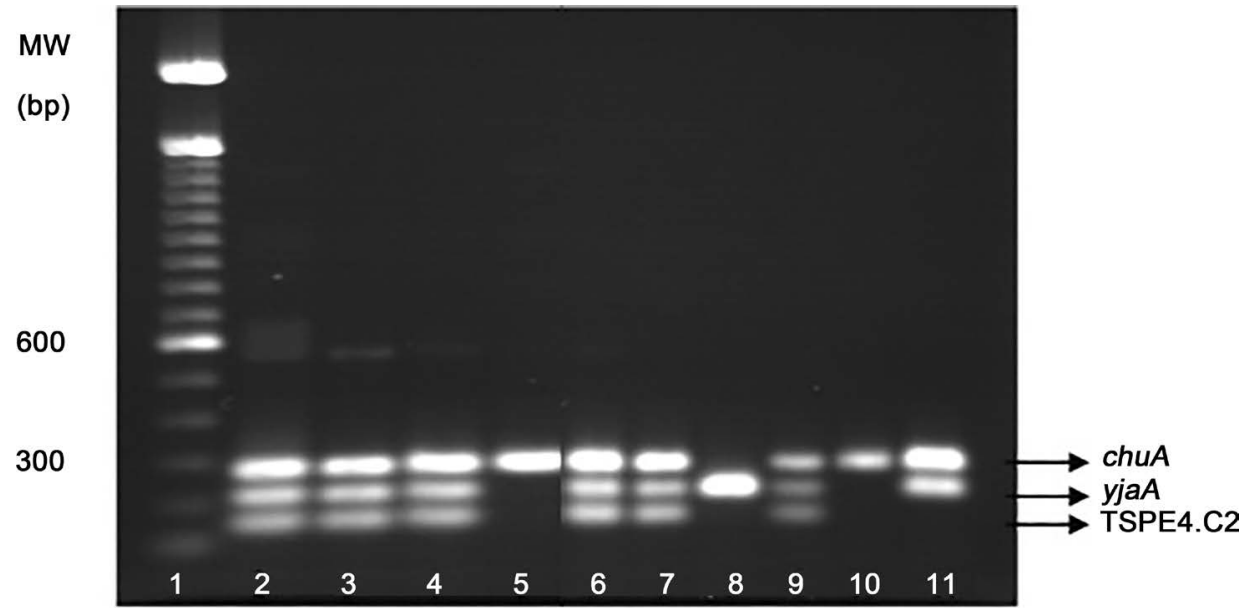

Lane 1: 100 bp DNA Ladder; Lane 2: L119C; Lane 3: I01; Lane 4: I07; Lane 5: I68; Lane 6: I49; Lane 7: I56; Lane 8: I59; Lane 9:I62; Lane 10: I19; Lane 11: I41.

Figure 3. Representative electrophoretic profiles of E. coli carrying phylogenetic markers.

urinary infection, as much in the HAM/TSP patients as in the asymptomatic patients, showed a wide distribution of the groups. The B2 group however, was the most prevalent. In the HAM/TSP patients with symptomatic UTI, 33.3\% belonged to the B2 group, $23.8 \%$ to the $\mathrm{A}$ and $\mathrm{B} 1$ groups, and $19.1 \%$ to the $\mathrm{D}$ group. Among bacterial isolates from individuals with asymptomatic UTI, the B2 and D groups were the highest represented, corresponding to $33.3 \%$, followed by groups $\mathrm{A}$ and $\mathrm{B} 1$, with $25 \%$, and $8.3 \%$ respectively. Epidemiological studies have shown that in patients with classic myelopathy, the greater majority present urinary symptomatology [5] [6] [26]. In patients without clinical symptoms for myelopathy (asymptomatic) the phylogenetic groups B2, $\mathrm{B} 1, \mathrm{D}$, and $\mathrm{A}$ were detected in $50 \%, 25 \%, 18.6 \%$, and $6.3 \%$ from the isolates recovered from patients with symptomatic UTI, respectively. Among patients without UTI symp- 
toms, the isolates showed the following distribution: B2 (45\%), D (30\%), A (20\%), and B1 (5\%). The E. coli isolates from recurrent infections with symptomatic and asymptomatic UTI conditions were characterized as belonging to the B2 and A/B1 groups, respectively. Our results confirm previous observations, highlighting the relevance of B2 phylogroups in urinary infections, reinforcing in this manner the role of this pathogenic lineage in the establishment of these infections. In the group of patients with more compromised neurological functioning (EDSS $>6$ ), the higher frequency was for isolates belonging to the A and B1 groups. These findings lead us to suggest that the vulnerability of the host could contribute to the establishment of the infection, given that these phylogenetic groups do not constitute typical agents for urinary infection. Different combinations in the genetic sequences chuA, yja $A$ and of the DNA fragment TSPE4.C2 allowed the characterization of the $E$. coli isolates in 8 phylotypes: --(5.6\%) and -+- (12.6\%) in group A, --+ (7.0\%) and -++ $(9.8 \%)$ in group B1, +++ $(32.3 \%)$ e $++-(7.0 \%)$ in group B2, +-- (15.4\%) and +-+ (9.8\%) in group D (Table 2). In the HAM/TSP group, we found the following phylotypes: --- (8.6\%) and -+(14.3\%) in group $\mathrm{A},--+(11.4 \%)$ and $-++(8.6 \%)$ in $\mathrm{B} 1,+++(28.6 \%)$ and $++-(2.8 \%)$ in $\mathrm{B} 2,+--(20 \%)$ and $+-+(5.7 \%)$ in $\mathrm{D}$. In the group of asymptomatic individuals, the same genetic variants were found, however with different frequency percentages: --$(2.8 \%)$ and $-+-(11.1 \%)$ in group $\mathrm{A},--+(2.8 \%)$ and $-++(11.1 \%)$ in $\mathrm{B} 1,+++(36.1 \%)$ and $++-(11.1 \%)$ in $\mathrm{B} 2,+--(11.1 \%)$ and $+-+(13.9 \%)$ in group $\mathrm{D}$ (Table 2$)$. In the whole population studied, the phylotype +++ was the most prevalent in the B2 group. In the phylogenetic $\mathrm{D}$ group, the phylotype +-- was the most prevalent among the HAM/TSP patients, and the +-+ allelic variant was the most common among the asymptomatic individuals. No statistical significance was observed in terms of the distribution of the phylotypes. The -++ variant of the B1 phylogroup had not been described in previous studies into pathogenic populations of E. coli [15] [16]. The phylogenetic characterization of the UPEC from HTLV-I+ patients was not previously reported; however, we mainly classified the isolates as belonging to the B2 phylogenetic group, where typically is classified uropathogenic populations of $E$. coli. The phylogenetic classification together with the diversity analysis permitted the elucidation of the clonal structure and the pathogenic potential of these microorganisms. Our results contributed to the molecular epidemiology of UPEC among HTLV-I+ individuals, showing that urinary infections due to E. coli, either recurrently manifested or not, are owed themselves to distinct bacterial lineages. Urinary symptoms have been described to negatively influence the quality of life of individuals infected by HTLV-I. Investments on therapeutic resources in order to decrease the risks of urinary infection, and preservation of a functional urinary system have been stimulated [8]. Studies seeking to investigate properties of virulence and resistance to antimicrobials of these uropathogens are currently under way in our laboratory. The data set obtained will be applicable to support epidemiological measures and public health monitoring, especially, together with therapeutic and preventative measures for these infections, which place at risk and compromise quality of life for these individuals. 


\section{Acknowledgements}

The authors are grateful to Rose Mary Pimentel Bezerra for technical support. This study was funded by Fundação de Amparo à Pesquisa no Rio de Janeiro, FAPERJ (grant number E-26/110.612/2012).

\section{References}

[1] Bangham, C.R.M., Yamano, A.A.Y. and Taylor, G.P. (2015) HTLV-1-Associated Myelopathy/Tropical Spastic Paraparesis. Nature Reviews Disease Primers, 1, 1-16.

https://doi.org/10.1038/nrdp.2015.23

[2] Proietti, F.A., Carneiro-Proietti, A.B., Catalan-Soares, B.C. and Murphy, E.L. (2005) Global Epidemiology of HTLV-I Infection and Associated Diseases. Oncogene, 24, 6058-6068. https://doi.org/10.1038/sj.onc. 1208968

[3] Jacobson, S. (1996) Cellular Immune Responses to HTLV-I: Immunopathogenic Role in HTLV-I-Associated Neurologic Disease. Journal of Acquired Immune Deficiency Syndromes and Human Retrovirology, 13, 100-106. https://doi.org/10.1097/00042560-199600001-00017

[4] Santos, S.B., Oliveira, P., Luna, T., Souza, A., Nascimento, M., Siqueira, I., Tanajura, D., Muniz, A.L., Glesby, M.J. and Carvalho, E.M. (2012) Immunological and Viral Features in Patients with Overactive Bladder Associated with Human T-Cell Lymphotropic Virus Type 1 Infection. Journal of Medical Virology, 84, 1809-1817. https://doi.org/10.1002/jmv.23341

[5] Castro, N.M., Rodrigues, W., Freitas, D.M., Muniz, A., Oliveira, P. and Carvalho, E.M. (2007) Urinary Symptoms Associated with Human T-Cell Lymphotropic Virus Type I Infection: Evidence of Urinary Manifestations in Large Group of HTLV-I Carriers. Urology, 69, 815-817. https://doi.org/10.1016/j.urology.2007.01.052

[6] Oliveira, P., Castro, N.M. and Carvalho, E.M. (2007) Urinary and Sexual Manifestations of Patients Infected by HTLV-I. Clinics, 62, 191-196.

https://doi.org/10.1590/S1807-59322007000200015

[7] Saito, M., Kondo, A., Kato, K. and Gotoh, M. (1991) Bladder Dysfunction Due to Human T-Lymphotrophic Virus Type I Associated Myelopathy. British Journal of Urology, 68, 365-368. https://doi.org/10.1111/j.1464-410X.1991.tb15351.x

[8] Andrade, R., Tanajura, D., Santana, D., Santos, D. and Carvalho, E.M. (2013) Association between Urinary Symptoms and Quality of Life in HTLV-1 Infected Subjects without Myelopathy. International Brazilian Journal of Urology, 39, 861-866.

https://doi.org/10.1590/S1677-5538.IBJU.2013.06.13

[9] Rocha, P.N., Rehem, A.P., Santana, J.F., Castro, N., Muniz, A.L., Salgado, K., Rocha, H. and Carvalho, E.M. (2007) The Cause of Urinary Symptoms among Human T Lymphotropic Virus Type I (HTLV-I) Infected Patients: A Cross Sectional Study. BMC Infectious Diseases, 12, 7-15.

[10] Ribas, J.G.R. and Melo, G.C.N. (2002). Human T-Cell Lymphotropic Virus Type 1 (HTLV1)-Associated Myelopathy. Revista da Sociedade Brasileira de Medicina Tropical, 35, 377384.

[11] Beike, M.A., Theall, K.P., O’Brien, M., Clayton, J.L., Benjamin, S.M., Winsor, E.L. and Kissinger, P.J. (2004) Clinical Outcomes and Disease Progression among Patients Coinfected with HIV and Human T Lymphotropic Virus Types 1 and 2. Clinical Infectious Diseases, 39, 256-263. https://doi.org/10.1086/422146

[12] Croxen, M.A. and Finlay, B.B. (2012) Molecular Mechanisms of Escherichia coli Pathoge- 
nicity. Nature Reviews Microbiology, 8, 26-38.

[13] Dobrindt, U. (2005) (Patho-)Genomics of Escherichia coli. International Journal of Medical Microbiology, 295, 357-371. https://doi.org/10.1016/j.ijmm.2005.07.009

[14] Clermont, O., Bonacorst, S. and Bingen, E. (2000) Rapid and Simple Determination of the Escherichia coli Phylogenetic Group. Applied and Environmental Microbiology, 66, 45554558. https://doi.org/10.1128/AEM.66.10.4555-4558.2000

[15] Gordon, D.M., Clermont, O., Tolley, H. and Denamur, E. (2008) Assigning Escherichia coli Strains to Phylogenetic Groups: Multi-Locus Sequence Typing versus the PCR Triplex Method. Environmental Microbiology, 10, 2484-2496. https://doi.org/10.1111/j.1462-2920.2008.01669.x

[16] Regua-Mangia, A.H., Irino, K., Pacheco, R.S., Bezerra, R.M.P., Périssé, A.R.S. and Teixeira, L.M. (2010) Molecular Characterization of Uropathogenic and Diarrheagenic Escherichia coli Pathotypes. Journal of Basic Microbiology, 50, S107-S115. https://doi.org/10.1002/jobm.200900364

[17] Johnson, J.R. and Stell, A. (2000) Extended Virulence Genotypes of Escherichia coli Strains from Patients with Urosepsis in Relation to Phylogeny and Host Compromise. The Journal of Infectious Diseases, 181, 261-272. https://doi.org/10.1086/315217

[18] Moulin-Schouleur, M., Répérant, M., Laurent, S., Brée, A., Mignon-Grasteau, S., Germon, P., Rasschaert, D. and Schouler, C. (2007) Extraintestinal Pathogenic Escherichia coli Strains of Avian and Human Origin: Link between Phylogenetic Relationships and Common Virulence Patterns. Journal of Clinical Microbiology, 45, 3366-3376. https://doi.org/10.1128/JCM.00037-07

[19] Kurtzke, J.F. (1983) Rating Neurologic Impairment in Multiple Sclerosis: An Expanded Disability Status Scale (EDSS). Neurology, 33, 1444-1452.

https://doi.org/10.1212/WNL.33.11.1444

[20] Regua-Mangia, A.H., Gomes, T.A., Vieira, M.A., Irino, K. and Teixeira, L.M. (2009) Molecular Typing and Virulence of Enteroaggregative Escherichia coli Strains Isolated from Children with and without Diarrhoea in Rio de Janeiro City, Brazil. Journal of Medical Microbiology, 58, 414-422. https://doi.org/10.1099/jmm.0.006502-0

[21] Nath, G., Maury, P., Gulati, A.K. (2010) Eric PCR and RAPD Based Fingerprinting of Salmonella Typhi Strains Isolated over a Period of Two Decades. Infection, Genetics and Evolution, 10, 530-536. https://doi.org/10.1016/j.meegid.2010.02.004

[22] Chaudhuri, R.R. and Henderson, I.R. (2012) The Evolution of the Escherichia coli Phylogeny. Infection, Genetics and Evolution, 12, 214-226. https://doi.org/10.1016/j.meegid.2012.01.005

[23] Bielaszewska, M., Dobrindt, U., Gärtner, J., Gallitz, I., Hacker, J., Karch, H., Müller, D., Schubert, S., Schmidt, M., Sorsa, L.J. and Zdziarski, J. (2007) Aspects of Genome Plasticity in Pathogenic Escherichia coli. International Journal of Medical Microbiology, 297, 625639. https://doi.org/10.1016/j.ijmm.2007.03.001

[24] Dale, A.P. and Woodford, N. (2015) Extra-Intestinal Pathogenic Escherichia coli (ExPEC): Disease, Carriage and Clones. Journal of Infection, 71, 615-626.

https://doi.org/10.1016/j.jinf.2015.09.009

[25] Juhas, M. (2015) Horizontal Gene Transfer in Human Pathogens. Critical Reviews in Microbiology, 41,101-108. https://doi.org/10.3109/1040841X.2013.804031

[26] Castro, N.V., Freitas, D.M., Rodrigues, W., Muniz, A., Oliveira, P. and Carvalho, E.M. (2007) Urodynamic Features of the Voiding Dysfunction in HTLV-I Infected Individuals. International Brazilian Journal of Urology, 33, 238-245. https://doi.org/10.1590/S1677-55382007000200016 
Submit or recommend next manuscript to SCIRP and we will provide best service for you:

Accepting pre-submission inquiries through Email, Facebook, LinkedIn, Twitter, etc. A wide selection of journals (inclusive of 9 subjects, more than 200 journals)

Providing 24-hour high-quality service

User-friendly online submission system

Fair and swift peer-review system

Efficient typesetting and proofreading procedure

Display of the result of downloads and visits, as well as the number of cited articles

Maximum dissemination of your research work

Submit your manuscript at: http://papersubmission.scirp.org/

Or contact aid@scirp.org 